\title{
Identifying and monitoring progress in collaboration skills
}

\author{
Dr Claire Scoular \\ Australian Council for Educational Research \\ https://doi.org/10.37517/978-1-74286-638-3_15
}

\begin{abstract}
Dr Claire Scoular's research interest revolves around the assessment and teaching of 21st-century skills. She has worked with numerous countries to identify and bridge the gap between their assessment, curriculum and pedagogy in relation to skills. In particular, she has led reviews and development of curriculum documentation, developed classroom-based assessment tools and generated teaching resources for skills including problem-solving, collaboration, learning in digital networks, critical thinking, creative thinking and self-regulation. She has been an active lecturer for many years and has developed courses in both traditional formats and online formats, including both the design of the content, and the assessment tasks. Her experience in psychometric assessment, intervention work and research spans across the UK, the Asia-Pacific and South America. She has undertaken consultancies for WorldBank, The Brookings Institution and UNESCO. Dr Scoular has been a Keynote Speaker on multiple occasions, and recently served as a presenter and mentor to delegates at the Y20 Youth Summit.
\end{abstract}

\section{Abstract}

The nature of skills such as collaboration is complex, particularly given that there are internal processes at play. Inferences need to be made to interpret explicit behaviours observed from intentionally designed assessment tasks. This paper centres on the approach to develop hypotheses of skill development into validated learning progressions using assessment data. Understanding a skill from a growth perspective is essential for the effective teaching and development of the skill. The application of Item Response Theory (IRT) allows the interpretation of assessment data as levels of proficiency that we can use to map or monitor progress in collaborative skills.

\section{Collaboration as an important skill for learning}

There is increasing demand to work well with others and to work globally (O'Neil et al., 2004). Consequently, collaboration skills that allow effective working in groups have been identified as increasingly important for success in education and work environments (Singh-Gupta \& TrouttErvin, 1996). As a result, educational research on collaboration has been in abundance in recent years (Griffin \& Care, 2015; Organisation for Economic Co-operation and Development [OECD], 2017 Scoular \& Care, 2019; von Davier \& Halpin, 2013). The OECD's decision to assess collaborative problem-solving (CPS) in the Programme for International Student Assessment (PISA) in 2015 has been a major driver in highlighting the importance of understanding and measuring this skill.

Collaboration has been shown to enhance cognitive development (Webb, 1989; Zhang, 1998) and has been demonstrated to have advantages in encouraging accountability, ability to ask questions and justify responses, flexibility in problem-solving and reflective skills (Baghaei et al., 2007; Soller 2001; Webb et al., 1998). Several prominent researchers highlighted the learning benefits to the individual of interaction with other humans, suggesting that placing learners in a social context is a core strategy for developing complex cognitive skills such as problem-solving competency (Glaser, 1992; Vygotsky, 1986; Wittrock, 1989). When learners work collaboratively to solve problems, they think through the problem and the processes more explicitly during their interaction with others, 
which leads to a greater conceptual understanding and more effective task management (DarlingHammond, 2003).

There is research to suggest that learners process information differently when they work in groups compared to working independently (King et al., 1997). Social interactions make learners' understanding explicit and learners usually improve their comprehension through discussion with others, elaborating, and negotiating with others to reach shared understanding (Van Boxtel et al., 2000). Collaborative actions, such as asking questions, peer mentoring, and providing feedback, can help learners to solve problems or finish tasks they may have otherwise not been able to solve or complete and, therefore, allow them to move towards higher levels of proficiency (King et al., 1997). Social interactions while working through complex tasks can provide additional ideas and shared meaning that an individual would not achieve without communicating with others (OECD, 2013).

In education systems around the world, teachers are being tasked with monitoring and improving students' collaboration skills (Scoular et al., 2020). One of the major challenges in that endeavour is identifying exactly what collaboration looks like in the classroom and how proficiency in it can be described. Beyond identifying the importance of collaboration, there is little guidance on where, when, and how to develop, teach and train such skills. This is partly due to a lack of understanding of the nature of the skills, including how it develops and changes over time, and which aspects are fundamental building blocks.

One challenge in measuring skills such as collaboration is that they are complex, particularly given there are internal processes at play. Evidence of ability in such skills is likely to be covert, not directly observable and, therefore, inferences about student ability need to be drawn from demonstrated behaviours observed from intentionally designed assessment tasks. Education systems frequently emphasise summative assessments that centre on overall score points. These serve a purpose but typically do not contribute to individual learning or development of growth in skills. Measuring an innovative domain requires innovative measures. Assessments of progress are an alternative to judging success only in terms of year-level standards. Identifying specifically what a learner needs to know or be able to do can better inform how instructional support can be adapted to support people to progress towards their goals. In other words, the focus should be on learning progressions, rather than just on the scores.

\section{Moving from conceptualisation to assessment data}

The definition of collaboration is much more complex than simply working with others. The literature has shifted from a simple definition of collaboration as working in groups, to defining collaboration as an action where two or more learners pool knowledge, resources and expertise from different sources in order to reach a common goal. The distinction between interdependence and independence provides some insight into the nature of collaboration. While the focus of team or group work literature has been on independent teams where learners work in relative isolation, interdependent teams rely on the actions of others and cannot perform activities independently (von Davier \& Halpin, 2013). Collaboration is interdependent. There is shared responsibility and an active division of labour. Although there are different definitions of collaboration presented in the literature, similar components can be identified in each (Hesse et al., 2015; OECD, 2017). For example, due to the nature of collaboration, the participation of each learner and their level of engagement with an activity directly impacts on the effectiveness of the collaborative group as a whole.

The definition of a skill has implications for assessment task design, and good measurement practice indicates that a clear definition of the domain the assessment is measuring should be identified before task design begins (Scoular et al., 2017). As a means to support teachers in understanding the skill in a detailed way, the Australian Council for Educational Research (ACER) produced a skill development framework for collaboration (Scoular et al., 2020). The purpose of the ACER framework is to establish a common terminology for describing collaboration, taking into 
consideration existing assessments of collaboration, and providing a structure that is suited for the ongoing assessment and teaching of collaboration. The framework breaks collaboration down into strands that are then further elaborated as aspects (see Figure 1). Within this collaboration definition, there is specification of three strands: building shared understanding, collectively contributing, and regulating, and within each strand there are associated aspects.

The framework also includes skill development levels that outline how growth in a particular aspect can be demonstrated, and how learners move from early to more advanced application and understandings. These levels support efforts to measure attainment and monitor learner growth over time, and are underpinned by an understanding that learners of the same age and in the same year of school can be at very different points in their learning and development. For this reason, the levels are deliberately not linked to years of schooling. The levels were initially hypothesised, using literature, research and expert judgement to build an understanding. To ensure an evidencebased approach, data from a number of assessments were then compared and contrasted to the hypothesised levels. Data were drawn from a number of sources, including ACER assessments and the PISA-CPS 2015 assessment data. The remainder of this paper will demonstrate an example of the approach taken.

Figure 1 Collaboration definitional framework

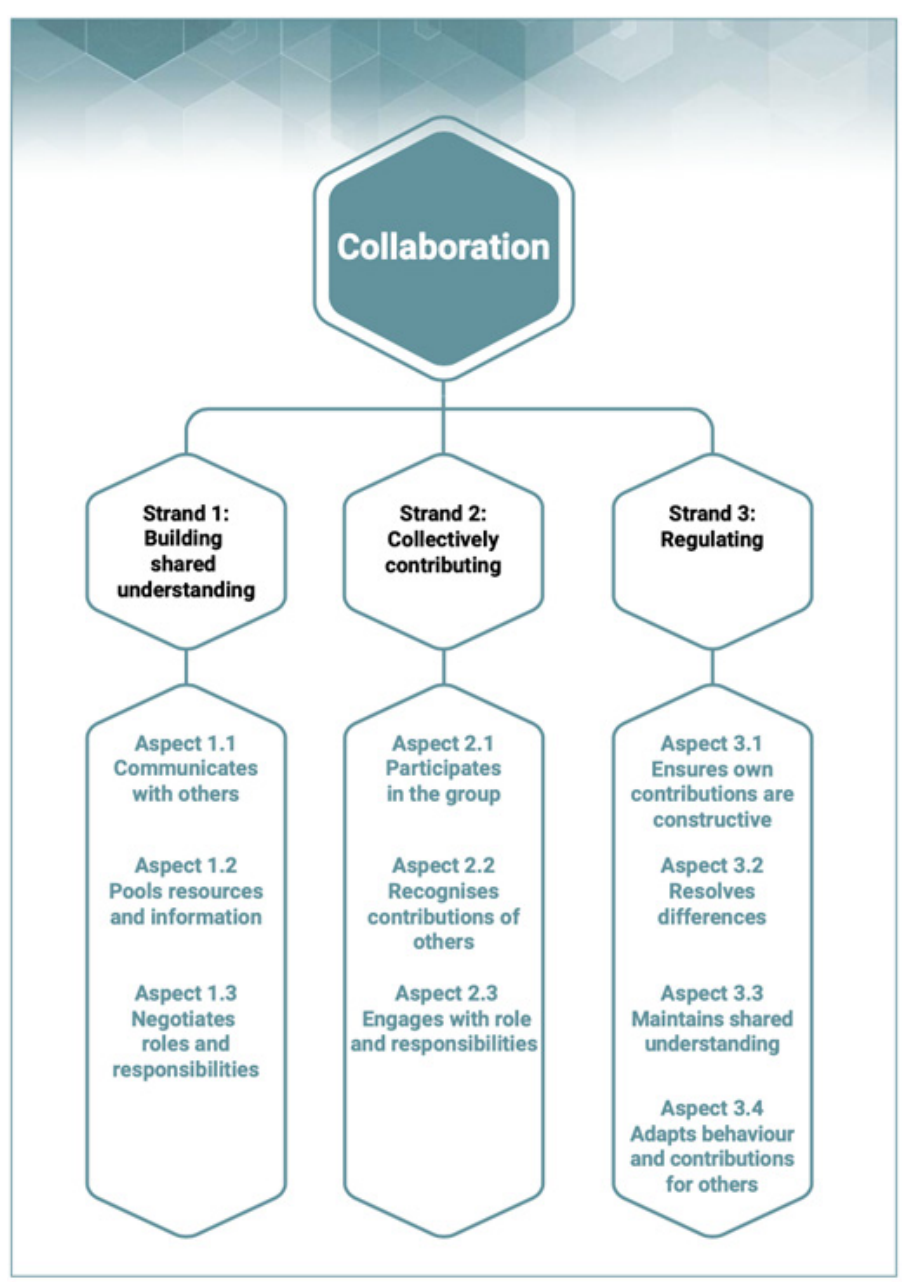

Source: Scoular et al (2020) 


\section{Wright map}

Item Response Theory (IRT) is a psychometric analysis often applied to assessments to examine item quality and identify student ability. One particular IRT output, the Wright map (Wilson \& Draney, 2002), is helpful for visualising the interaction between different items, and their estimated difficulties, in relation to student ability. The Wright map places coded responses to items and learner estimates onto a single scale, using logits as the scaling unit (an arbitrary unit used to enable location of the two variables on the same metric). It presents the items in increasing order of sophistication in relation to learner ability and can be viewed as two vertical histograms.

An example Wright map for a collaboration assessment included in our validation process is presented in Figure 2. The left side of the figure displays the distribution of learner ability as a histogram and the right side of the figure displays the distribution of the item difficulties. Items 32.2, 38.2 and 50.2 are at the top of the map indicating they are the most difficult. Items 11.1, 12, 19.1 and 40 are at the bottom of the map indicating they were the easiest. The learner ability distribution extends slightly lower than these items so it is difficult to discriminate between those learners at this very low level, although there are only a few of them.

Figure 2 Wright map for a collaboration assessment

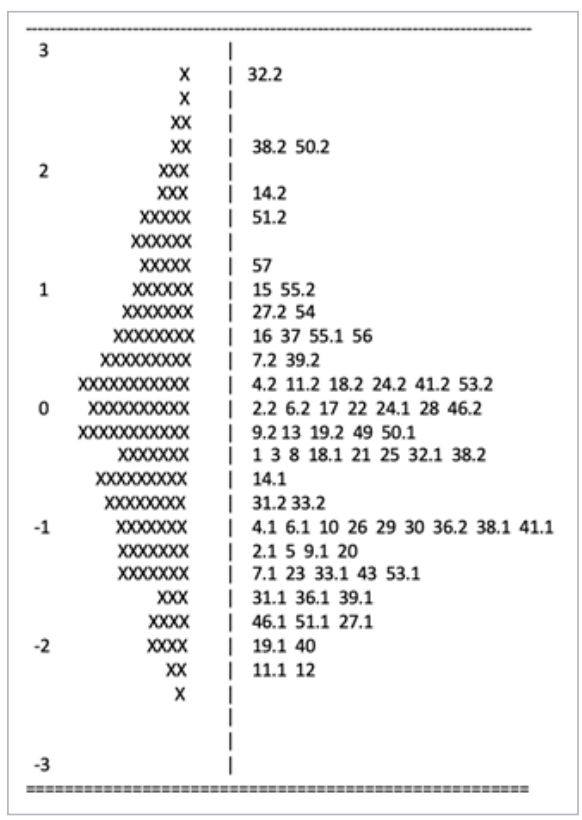

\section{Moving from assessment data to understanding skill development}

The Wright map gives a numerical scale of increasing proficiency or ability in the domain, and it supports a qualitative understanding of different parts of that scale by looking at the differently coded responses to the items, or statements about the substance of differently coded responses to items, that are ranged along the scale. When a learner's ability is estimated, the probability of item response success can be identified by referencing the corresponding learner and item locations on the Wright map. This unidimensionality, and the relative locations of items and learners along its continuum, provides crucial information in understanding the skill and its structure. That is, the data presented by the Wright map allow us to understand the domain as a continuum.

As presented in Figure 3, for example, the location of the coded responses to the items and what aspects they are mapped to can tell us a great deal about proficiency in collaboration. Item 11 
is mapped to Aspect 1.1 'communicates with others' in the collaboration framework. A coded response of 1 on this item (denoted 11.1) is specifically the behaviour 'responding to questions from others' and is considered within the ACER framework to be a behaviour associated with relatively low proficiency in collaboration. This item is quite far down the Wright map suggesting that it was a fairly easy item, and that corroborates our assumption. By comparison, a coded response of 2 (denoted 11.2) is a behaviour associated with relatively higher proficiency within this aspect, 'initiates communication with others', and it is much higher up the Wright map suggesting it is indeed a more difficult item. This suggests that there are different levels of proficiency within aspects; for example, less proficient learners would only communicate with others when they are responding to questions, whereas more proficient learners would initiate communication with and between group members. Similarly, difference levels of proficiency can be interpreted from item 14, which is mapped to Aspect 3.2 'resolves differences'. A lower score on this item (denoted 14.1) is in the lower half of the Wright map and is measuring learners attempting but failing negotiations. By comparison, a higher score on this item (denoted 14.2) is one of the most difficult items at the top of the Wright map and is measuring 'resolves conflicts'. These item locations suggest that less proficient learners attempt to negotiate with others but often cannot resolve differences, in contrast to highly proficient learners who can resolve differences.

Figure 3 Interpreting specific items' difficulty in the Wright map

\begin{tabular}{|c|c|c|c|}
\hline \multirow[t]{5}{*}{3} & & | & \\
\hline & $\mathrm{x}$ & | 32.2 & \\
\hline & $\mathrm{x}$ & i & \\
\hline & $x x$ & i & \\
\hline & $x x$ & | 38.250 .2 & \\
\hline \multirow[t]{5}{*}{2} & $x x x$ & & \\
\hline & $x x x$ & i (14.2) & \multirow{2}{*}{ Resolves conflicts (Aspect 3.2) } \\
\hline & $x x x x x$ & 51.2 & \\
\hline & $x x x x x x$ & i & \\
\hline & $x x x x x$ & | 57 & \\
\hline \multirow[t]{5}{*}{1} & $x x x x x x$ & 1555.2 & \\
\hline & $x x x x x x x$ & 27.254 & \\
\hline & $x x x x x x x x$ & 163755.156 & \\
\hline & $x x x x x x x x x$ & 7.239 .2 & \multirow{3}{*}{$\begin{array}{l}\text { Initiates communication with others } \\
\text { (Aspect 1.1) }\end{array}$} \\
\hline & $x x x x x x x x x x x$ & ) 4.2 (11.2) $180-24.2-41.2-5.32$ & \\
\hline \multirow[t]{4}{*}{0} & 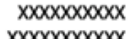 & $\begin{array}{l}2.26 .21722 \quad 24.12846 .2 \\
9.213 \quad 19.2\end{array}$ & \\
\hline & $\begin{array}{r}x x x x x x x x x x \\
x x x x x x x\end{array}$ & 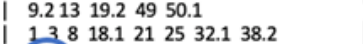 & \multirow{3}{*}{$\begin{array}{l}\text { Attempted but failed negotiation } \\
\text { (Aspect 3.2) }\end{array}$} \\
\hline & $x x x x x x x x x$ & (14.1) & \\
\hline & $x x x x x x x x$ & | 31.233 .2 & \\
\hline \multirow[t]{5}{*}{-1} & $x x x x x x x$ & | $4.16 .11026 \quad 293036.238 .141 .1$ & \\
\hline & $x x x x x x x$ & | 2.159 .120 & \\
\hline & $x x x x x x x$ & | 7.12333 .14353 .1 & \\
\hline & $x \mathrm{xx}$ & | 31.136 .139 .1 & \\
\hline & $x x x x$ & | 46.151 .127 .1 & \\
\hline-2 & $x 0 x x$ & 19.140 & \multirow{2}{*}{$\begin{array}{l}\text { Responds to questions from others } \\
\text { (Aspect 1.1) }\end{array}$} \\
\hline & $\begin{array}{r}x x \\
x\end{array}$ & (11.1) $1 \%$ & \\
\hline & & i & \\
\hline-3 & 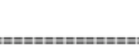 & | & \\
\hline
\end{tabular}

The Wright map presented in this paper allows interpretation of the ordering of the items as a progression of collaborative skill. The positioning of items on that continuum can be interpreted to better understand the domain at different levels of proficiency. This allows meaningful information about what learners can and cannot do given their ability estimates to be relayed back to educators, and to learners themselves. As the item examples in this paper relate to behaviours, it can provide educators with real-time data regarding the social and cognitive behaviours their learners are demonstrating. This level of information extends beyond that gathered and interpreted through static tasks or multiple-choice tests. If the expectation of educators is to teach skills such as collaboration, then detailed data about what their learners can demonstrate is imperative and can complement the evidence already being gathered. Having knowledge of the behaviours expected at higher levels of ability can help educators to develop and implement instructional activities that are targeted to learner needs. 
It is also possible to interpret the Wright map as levels of proficiency by interpreting groups of items where they appeared to cluster at similar levels on the scale. Figure 4 identifies cut off points on the scale where natural breaks appear between clusters of items that have similar item difficulty levels. These lines indicate where a discernible change in item difficulty was associated with a change in the kind of skill (or ability) required to demonstrate the associated behaviours. These cut scores and clusters of indicators enable an interpretation of the scale as a developmental progression (Griffin, 2007).

Figure 4 Interpreting proficiency from the Wright map

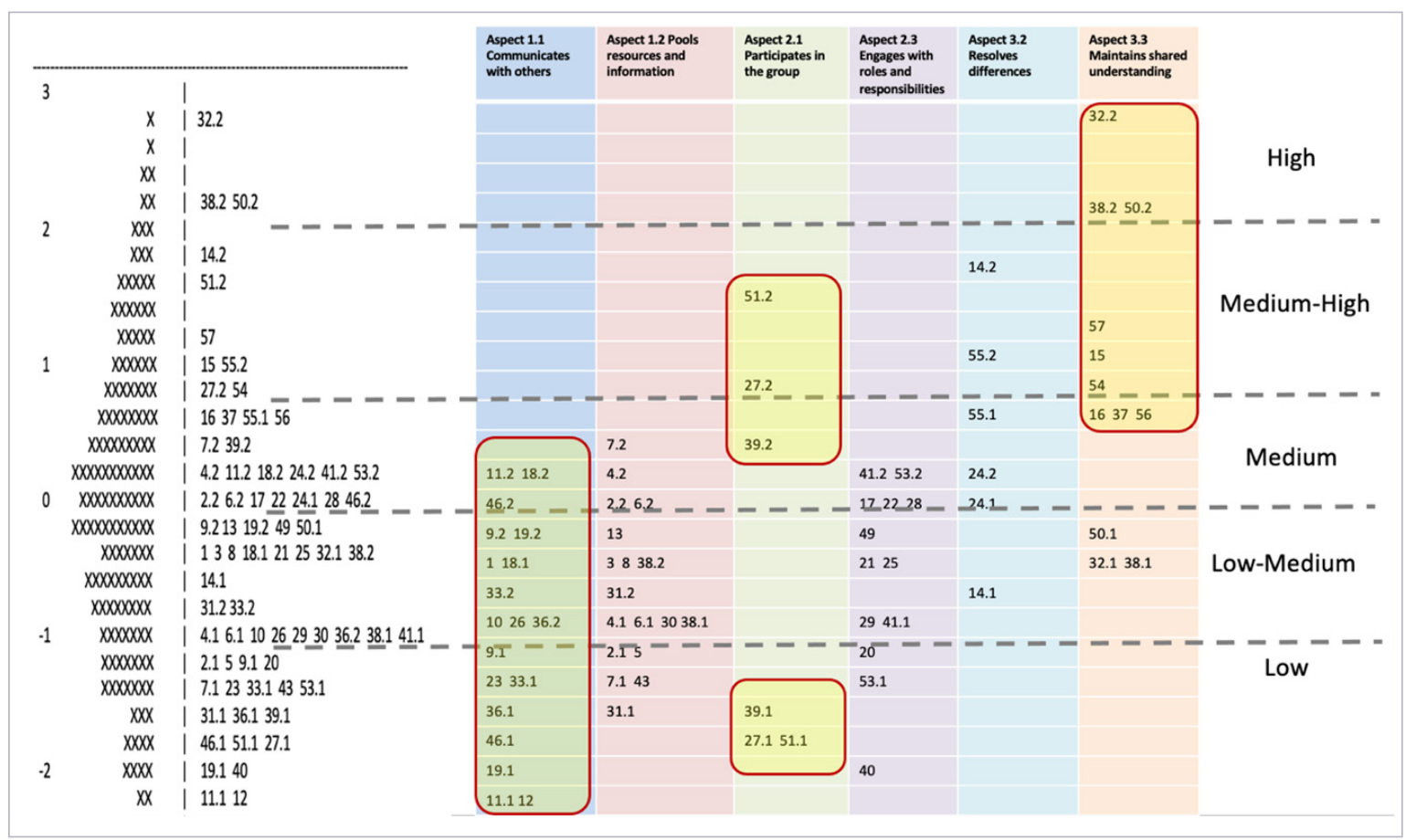

Interpretation of the items and where they are clustered on the map can lead to the production of text descriptions of what is occurring at each level. The descriptions can be interpreted as level of progress in collaboration from novices (A) to experts (E). For example, novices would work independently, unaware of the benefit of engaging with peers, and thus would not be likely to solve a problem collaboratively. As learners increase in proficiency, they engage more with others and gradually realise the benefit of collaboration. Expert collaborators depend upon their peers, develop a mutual understanding of problems or tasks, and work strategically through them together. Negotiation is a critical component of collaboration, but only proficient learners can harness conflicts towards a positive outcome.

\section{A broader sense of the skill}

It is important to note that the skill just discussed is interpreted through the lens of a single assessment. It is likely that not every item in a cluster will tell the same conceptual story as the others. While the item may fit statistically, it can be omitted from this part of the interpretation on conceptual grounds. Similarly, no single assessment is expected to measure the entirety of a domain. For example, the assessment example used in this paper did not measure Aspect 3.4 'adapts behaviours and contributions for others' or Aspect 1.3 'negotiates roles and responsibilities'. Therefore, interpreting a single assessment in terms of proficiency levels will likely present gaps in the representation of the skill as a whole. 
In order to get a broader sense of a skill, learning progressions can be developed by drawing on response data from multiple assessments and expert judgement. Learning progressions are not the same as, or extensions of, learning standards; rather, they focus explicitly on the building blocks learners need to master before they can achieve complex skill forms. When assessments provide information about where learners are in their understanding at the time of assessment, they also provide a basis for monitoring individual progress over time. However, it is important to note that learning progressions are not intended to describe a single pathway to achieving proficiency in a skill that it is assumed all learners will follow. Instead, a learning progression describes a typical pathway that provides a good starting point for deeper interrogation of learners' unique pathways.

Table 1 presents an excerpt from the ACER skill development levels for the three strands of collaboration. This representation of learning progress for collaboration has been developed and validated using data from multiple assessments, including the Wright map presented in this paper (Scoular et al., 2020). The levels are intended to support understanding of the skills and the ways in which they develop. They can also support teachers to identify gaps in a learning area, where some learners may require further assistance in order to move learning forward along this path.

Table 1 Excerpt from collaboration learning progression

\begin{tabular}{|c|c|c|c|}
\hline Skill level & $\begin{array}{l}\text { Building shared } \\
\text { understanding }\end{array}$ & Collectively contributing & Regulating \\
\hline Medium & $\begin{array}{l}\text { Learners ask for } \\
\text { justification of responses } \\
\text { or perspective provided } \\
\text { (Aspect 1.1) }\end{array}$ & $\begin{array}{l}\text { Learners acknowledge that } \\
\text { others may have a different } \\
\text { perspective, and that based } \\
\text { on these perspectives, others' } \\
\text { contributions may be beneficial } \\
\text { to the group as a whole. They } \\
\text { understand and incorporate } \\
\text { the contributions of others into } \\
\text { their own work. (Aspect } 2.2 \text { ) }\end{array}$ & $\begin{array}{l}\text { Learners identify their own } \\
\text { strengths and weaknesses } \\
\text { in relation to the progress of } \\
\text { the group task as a whole. } \\
\text { (Aspect 3.1) } \\
\text { Learners make constructive } \\
\text { but unsuccessful attempts to } \\
\text { resolve differences. (Aspect 3.2) } \\
\text { Learners act to maintain shared } \\
\text { understandings, such as by } \\
\text { reiterating and finalising goals, } \\
\text { strategy, and roles in more } \\
\text { complex tasks. (Aspect 3.3) } \\
\text { Learners require feedback } \\
\text { from others or explicit requests } \\
\text { before they modify or tailor } \\
\text { their communication style or } \\
\text { behaviour. (Aspect 3.4) }\end{array}$ \\
\hline Low-mid & $\begin{array}{l}\text { Learners ask questions } \\
\text { or for clarification } \\
\text { from others. They will } \\
\text { communicate about the } \\
\text { related task and respond } \\
\text { to contributions of others. } \\
\text { (Aspect 1.1) } \\
\text { Learners identify that } \\
\text { they may not have all of } \\
\text { the information required } \\
\text { and pool some resources } \\
\text { and information with } \\
\text { others. (Aspect 1.2) } \\
\text { Learners negotiate roles } \\
\text { but without considering } \\
\text { the expertise, information } \\
\text { or skills help by other } \\
\text { group members. } \\
\text { (Aspect 1.3) }\end{array}$ & $\begin{array}{l}\text { Learners participate in all } \\
\text { necessary tasks throughout } \\
\text { the tasks. Learners maintain } \\
\text { a single strategy throughout. } \\
\text { Learners collaborate } \\
\text { successfully to achieve } \\
\text { a straightforward goal. } \\
\text { (Aspect 2.1) } \\
\text { Learners understand that } \\
\text { others may have an alternative } \\
\text { perspective. They listen to and } \\
\text { acknowledge the perspective } \\
\text { of others. (Aspect } 2.2 \text { ) } \\
\text { Learners show a willingness } \\
\text { and readiness to be involved } \\
\text { in the group. They take } \\
\text { responsibility for some of the } \\
\text { actions determined by their role } \\
\text { and provide feedback on their } \\
\text { individual task. (Aspect } 2.3 \text { ) }\end{array}$ & $\begin{array}{l}\text { Learners reflect on the quality } \\
\text { and relevance of their own } \\
\text { contributions. (Aspect 3.1) } \\
\text { Learners discuss differences } \\
\text { of opinion or perspective } \\
\text { with others and give careful } \\
\text { consideration of the views } \\
\text { of others. They comment } \\
\text { on differences but are often } \\
\text { unable to resolve them. } \\
\text { (Aspect 3.2) } \\
\text { Learners act to maintain } \\
\text { shared understanding through } \\
\text { reiterating goals, strategy and } \\
\text { roles in basic tasks. (Aspect 3.3) }\end{array}$ \\
\hline
\end{tabular}

Source: (from Scoular et al., 2020) 


\section{Conclusion}

It is increasingly apparent that our understanding of complex skills needs to be enhanced in order to meet the demand of 21st-century education (Griffin \& Care, 2015; OECD, 2017, Scoular \& Care, 2019; von Davier \& Halpin, 2013). Complex skills such as collaboration can be difficult to teach and learn, but the approach presented in this paper demonstrates that robust measurements can be developed that provide insight into how these skills can be demonstrated. Further, assessment data can actually provide more information and improve understanding of such complex skills. The ACER skill development framework for collaboration sets out behaviours and processes that can be associated with aspects of collaboration, and assessment data provide validation of this. No single assessment can paint the larger picture, but each individual assessment of collaboration can provide a piece of the puzzle in understanding this complex skill. Interpretations of the data visualisations such as the Wright maps can indicate how different proficiencies of collaboration might be demonstrated. Assessment of such skills, particularly in relation to growth, can shed light on how to appropriately situate teaching interventions and to identify learning in an innovative domain. The work ahead is iterative. Our understanding of 21st-century skills needs to be documented so that tasks can be designed appropriately to match this understanding. The more we develop robust assessments of 21 st-century skills, the more we can corroborate, validate, and evolve that understanding. If we are to continue to value these skills in the 21st century and beyond, efforts in understanding how they develop and what different levels of proficiency look like will need to be applied.

\section{References}

Baghaei, N., Mitrovic, A., \& Irwin, W. (2007). Supporting collaborative learning and problem solving in a constraint-based CSCL environment for UML class diagrams. International Journal on ComputerSupported Collaborative Learning, 2(2), 159-190. https://doi.org/10.1007/s11412-007-9018-0

Darling-Hammond, L. (2003). The learning classroom: Theory into practice. School of Education, Standford University. https://www.learner.org/courses/learningclassroom/support_pages/index. html

Glaser, B. (1992). Basics of grounded theory analysis. Sociology Press.

Griffin, P. (2007). The comfort of competence and the uncertainty of assessment. Studies in Educational Evaluation, 33, 87-99. https://doi.org/10.1016/j.stueduc.2007.01.007

Griffin, P., \& Care, E. (2015). Assessment and teaching 21st century skills: Methods and approach. Springer. https://doi.org/10.1007/978-94-017-9395-7

Hesse, F., Care, E., Buder, J., Sassenberg, K., \& Griffin, P. (2015). A framework for teachable collaborative problem solving skills. In P. Griffin \& E. Care (Eds.), Assessment and teaching of 21st century skills: Methods and approach (pp. 37-56). Springer. https://doi.org/10.1007/978-94-0179395-7_2

King, F. J, Rohani, F., \& Goodson, L. (1997). Statewide assessment of listening and verbal communication skills, information literacy skills, and problem-solving skills. Florida State University.

O'Neil, H. F., Chuang, S., \& Chung, G. K. W. K. (2004). Issues in the computer-based assessment of collaborative problem solving. Assessment in Education, 10, 361-373. https://doi. org/10.1080/0969594032000148190 
Organisation for Economic Co-operation and Development. (2013). PISA 2015: Draft collaborative problem solving framework. http://www.oecd.org/callsfortenders/Annex\%20ID_PISA\%202015\%20 Collaborative\%20Problem\%20Solving\%20Framework\%20.pdf

Organisation for Economic Co-operation and Development (OECD). (2017). PISA 2015 Results (Volume V): Collaborative problem solving. OECD Publishing. https://doi. org/10.1787/9789264285521-en

Scoular, C., \& Care, E. (2019). A generalized scoring process to measure collaborative problem solving in online environments. Educational Assessment, 1-22. https://doi.org/10.1080/10627197. 2019.1615372

Scoular, C., Care, E., \& Hesse, F. (2017). Designs for operationalizing collaborative problem solving for automated assessment. Journal of Educational Measurement, 54(1), 12-35. https://doi. org/10.1111/jedm.12130

Scoular, C., Duckworth, D., Heard, J., \& Ramalingam, D. (2020). Collaboration: Skill development framework. Australian Council for Educational Research. https://research.acer.edu.au/ar_misc/42

Scoular, C., Eleftheriadou, S., Ramalingam, D., \& Cloney, D. (2020). Comparative analysis of student performance in collaborative problem solving: What does it tell us? Australian Journal of Education, 64(3), 282-303. https://doi.org/10.1177/0004944120957390

Singh-Gupta, V., \& Troutt-Ervin, E. (1996). Preparing students for teamwork through collaborative writing and peer review techniques. Teaching English in the Two Year College, 23(2), 127-136.

Soller, A. (2001). Supporting social interaction in an intelligent collaborative learning system. International Journal of Artificial Intelligence in Education, 12(1), 40-62.

Van Boxtel, C., Van der Linden, J., \& Kanselaar, G. (2000). Collaborative learning tasks and the elaboration of conceptual knowledge. Learning and Instruction, 10(4), 311-330.

Vygotsky, L. S. (1986). Thought and language. The MIT Press.

Webb, N. M. (1989). Peer interaction and learning in small groups. International Journal of Education Research, 13, 21-39. https://doi.org/10.1016/0883-0355(89)90014-1

Webb, N. M., Nemer, K. M., Chizhik, A. W., \& Sugrue, B. (1998). Equity issues in collaborative group assessment: Group composition and performance. American Educational Research Journal, 35(4), 607-651. https://doi.org/10.3102/00028312035004607

Wilson, M., \& Draney, K. (2002). A technique for setting standards and maintaining them over time. In S. Nishisato, Y. Baba, H. Bozdogan, \& K. Kanefugi (Eds.), Measurement and multivariate analysis (pp. 325-332). Springer-Verlag.

Wittrock, M. C. (1989). Generative processes of comprehension. Educational Psychologist, 24(4), 345-376. https://doi.org/10.1207/s15326985ep2404_2

Zhang, J. (1998). A distributed representation approach to group problem solving. Journal of American Society of Information Science, 49(9), 801-809. https://doi.org/10.1002/(SICI)10974571(199807)49:9<801::AID-ASI5>3.0.C0;2-Q 